
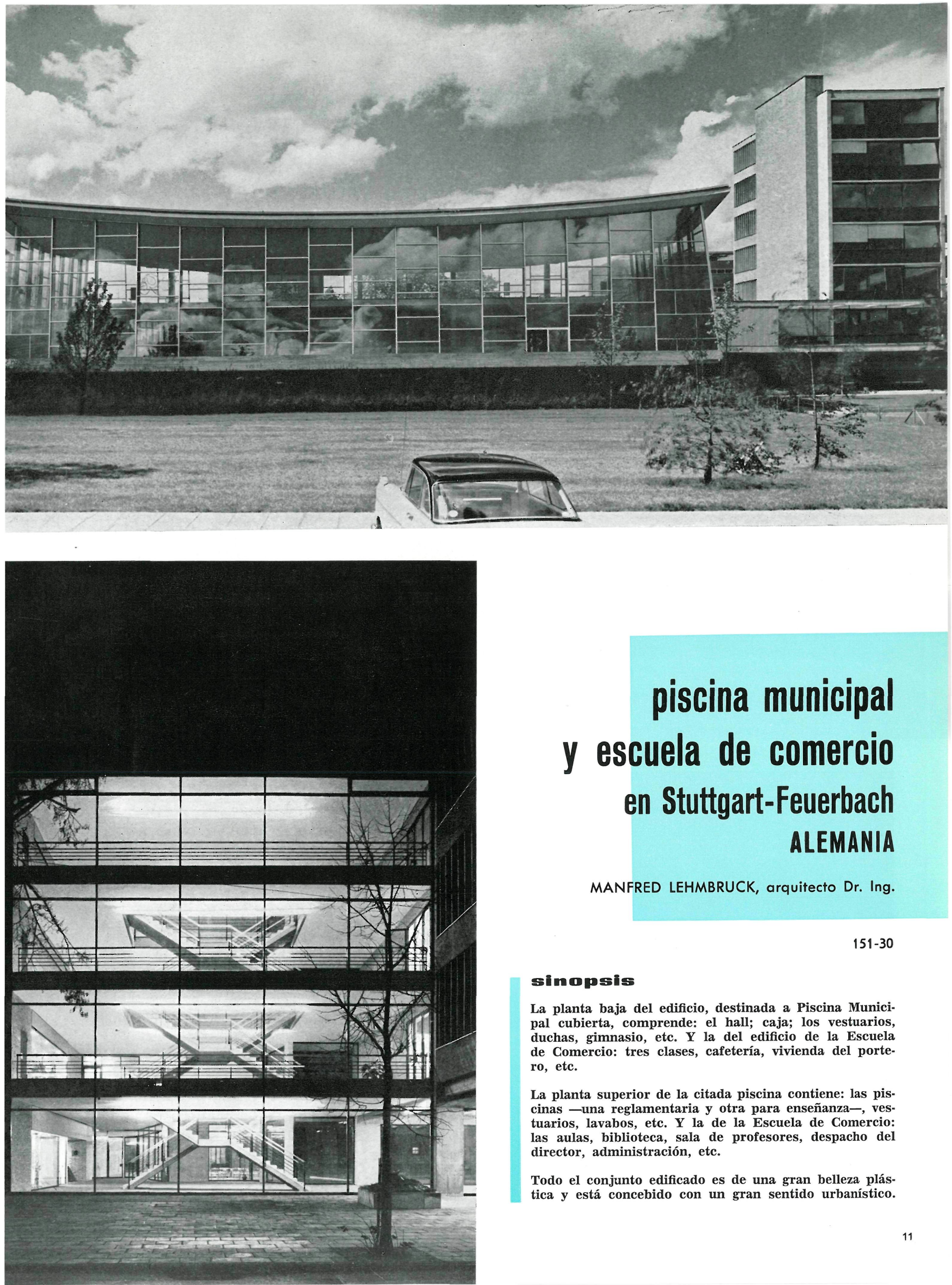

\title{
piscina municipal y escuela de comercio en Stuttgart-Feuerbach ALEMANIA
}

MANFRED LEHMBRUCK, arquitecto Dr. Ing.

$151-30$

\section{sinopsis}

La planta baja del edificio, destinada a Piscina Municipal cubierta, comprende: el hall; caja; los vestuarios, duchas, gimnasio, etc. $Y$ la del edificio de la Escuela de Comercio: tres clases, cafetería, vivienda del portero, etc.

La planta superior de la citada piscina contiene: las piscinas - una reglamentaria y otra para enseñanza-, ves tuarios, lavabos, etc. Y la de la Escuela de Comercio: las aulas, biblioteca, sala de profesores, despacho del director, administración, etc.

Todo el conjunto edificado es de una gran belleza plás tica y está concebido con un gran sentido urbanístico. 

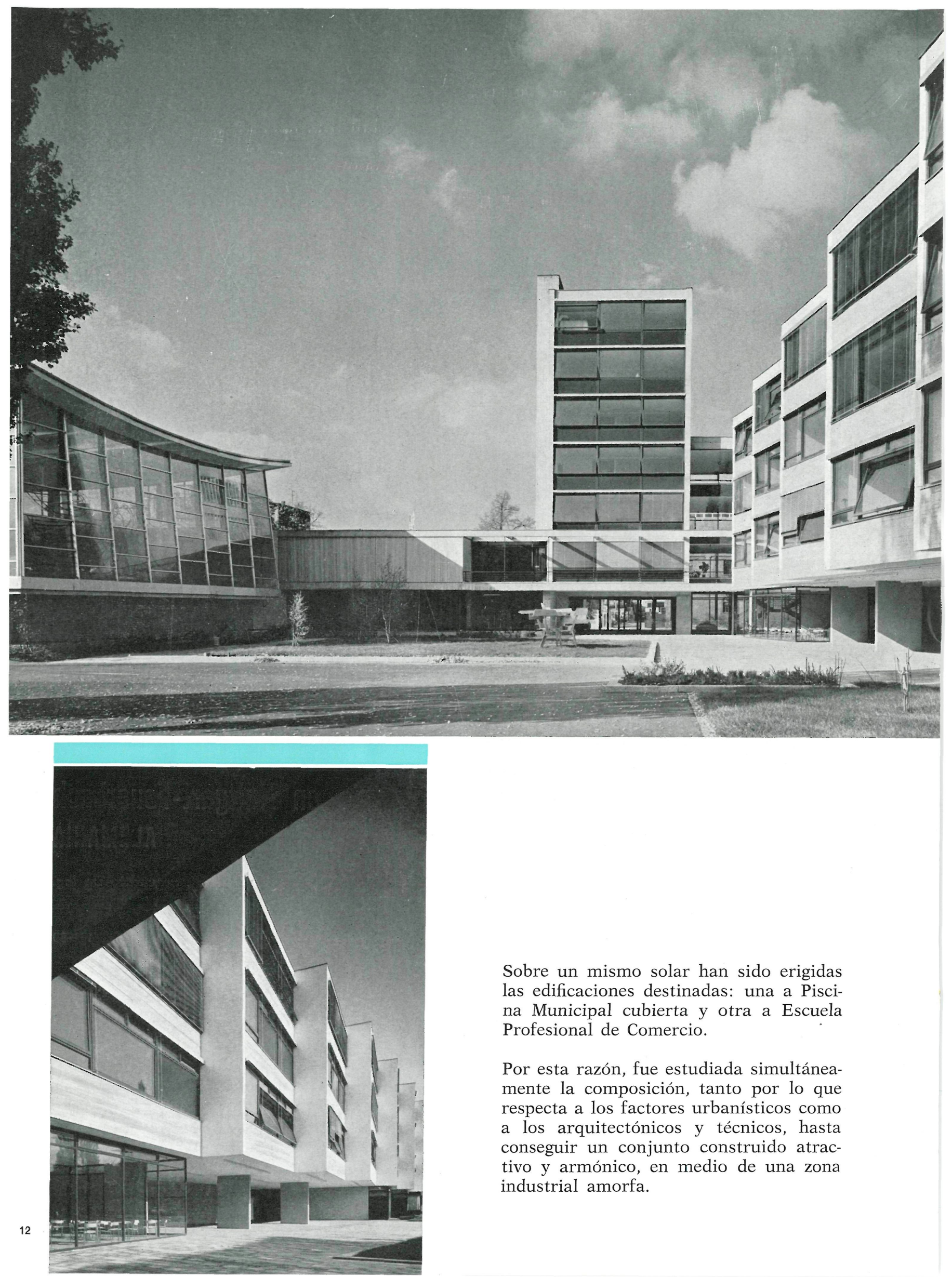

Sobre un mismo solar han sido erigidas las edificaciones destinadas: una a Piscina Municipal cubierta y otra a Escuela Profesional de Comercio.

Por esta razón, fue estudiada simultáneamente la composición, tanto por lo que respecta a los factores urbanísticos como a los arquitectónicos y técnicos, hasta conseguir un conjunto construido atractivo y armónico, en medio de una zona industrial amorfa. 

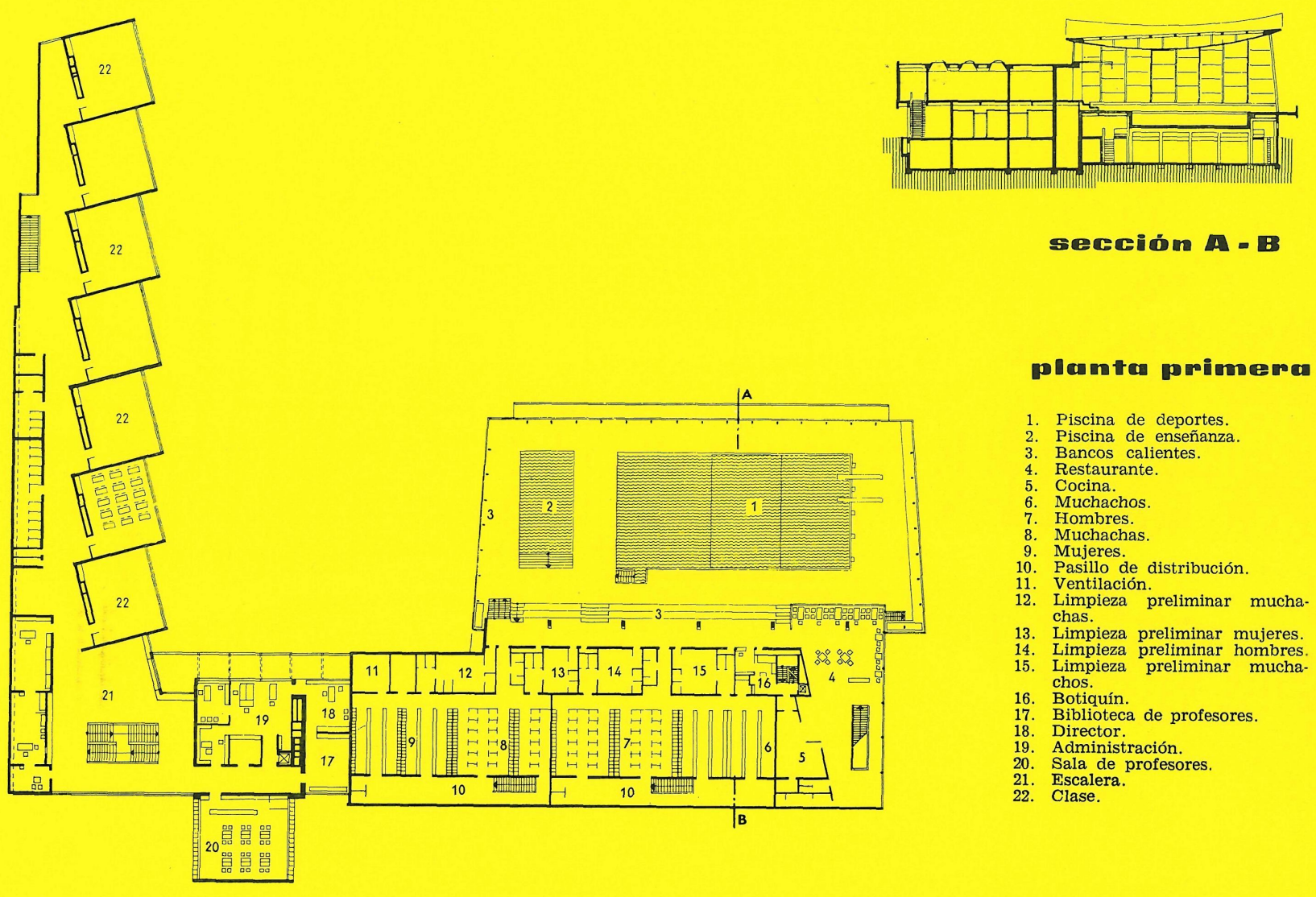

scceión $4=$

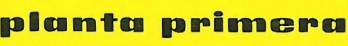

1. Piscina de deportes.

2. Pancos colientes.

4. Restaurante.

5. Cocina.

6. Muchachos

7. Hombres.

8. Muchachas.

10. Pasillo de distribución.

11. Ventilación.

12. Limpieza preliminar mucha chas.

13. Limpieza preliminar mujeres.

4. Limpieza preliminar hombres

15. Limpieza preliminar mucha-

16. Botiquín.

16. Botiquín.
17. Biblioteca de profesores.
18. Director.

19. Administración.

20. Sala de profesores.

21. Escalera.
22. Clase.

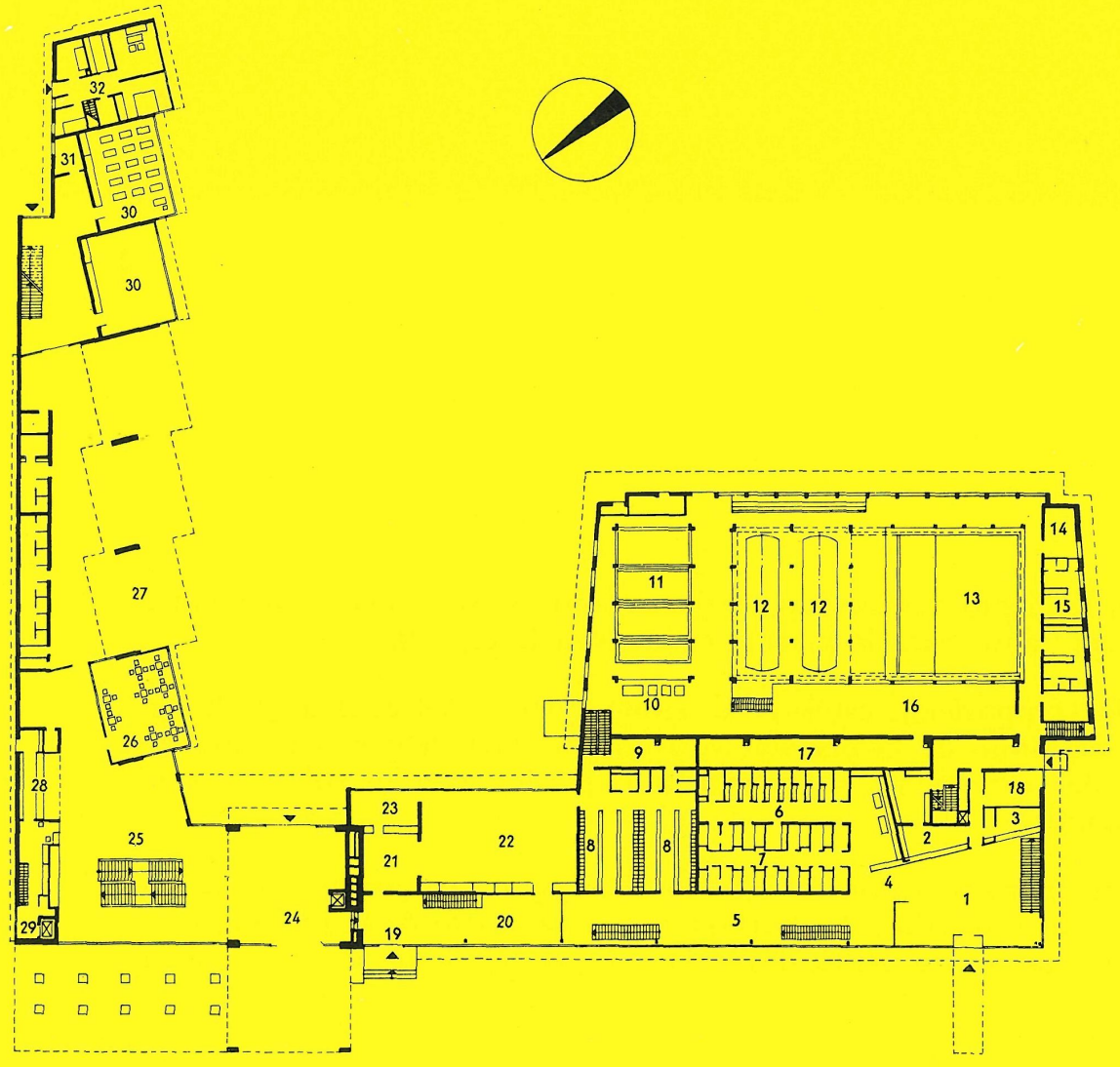

pllanta locio

1. Entrada

3. Vaja.

4. Control.

5. Vestíbulo

6. Duchas.

7. Baños.

Vestuario alumnos

9. Limpieza preliminar alumnos.

10. Sala de bombas.

11. Filtros.

13. Parte prof.

13. Parte profunda.

14. Sala de reuniones.

16. Pasillo de montaje.

17. Canal de ventilación.

18. Vigilante instala

19. Entrada clubs

20. Vestíbulo.

21. Sala de

23. Gimnasio

24. Entrada colegio.

25. Escalera.

26. Estar.

27. Recreo cubierto.

28. Bar

29. Portero.

31. Almacén.

32. Vivienda portero. 


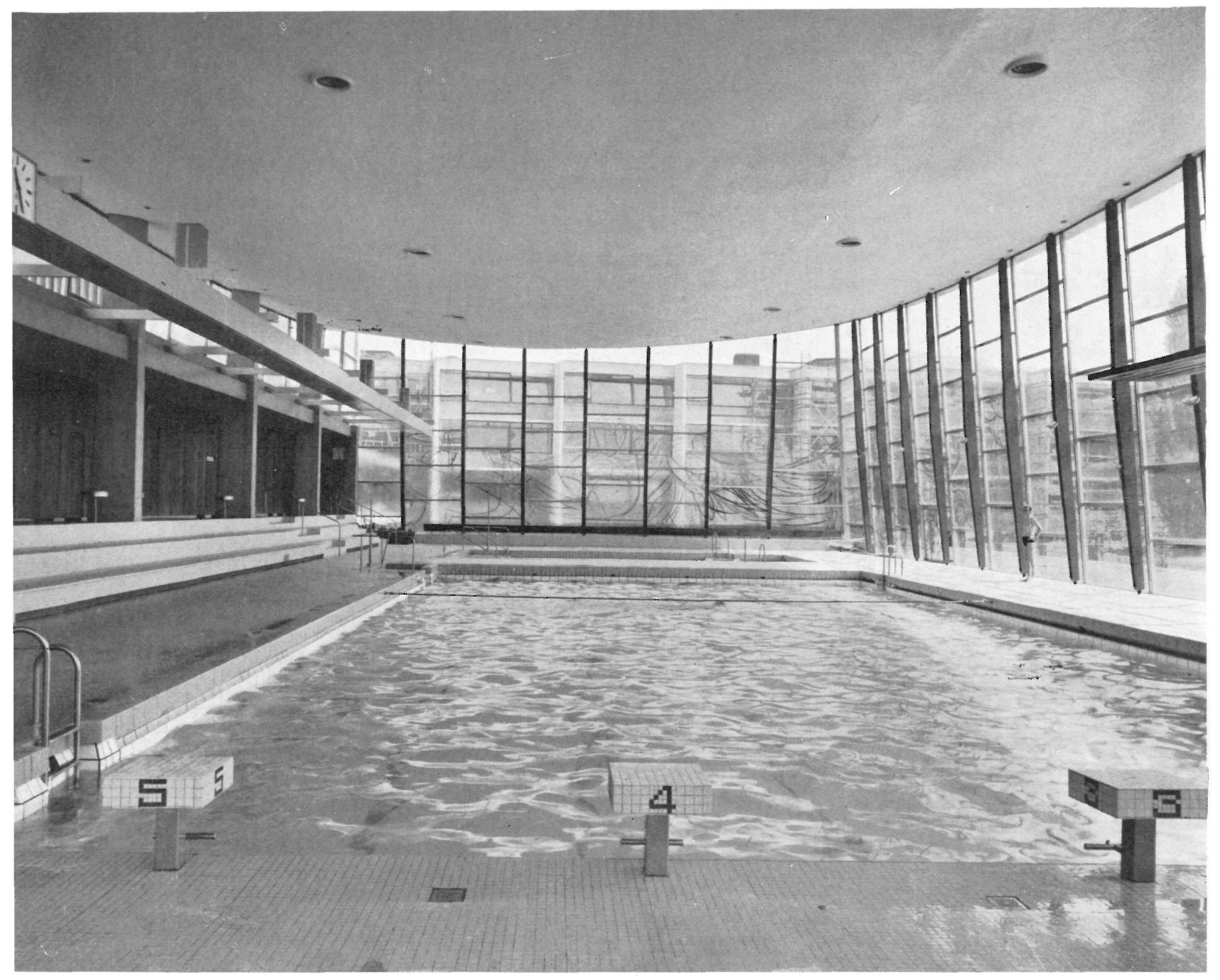

Fotos: GOTTFRIED PLANCK Y ZWIETASCH

A pesar del gran aprovechamiento del terreno, se ha creado, al sur, una zona al aire libre, de suma importancia, tanto para la piscina como para la escuela.

Por lo que respecta a la composición estética: el ritmo vertical del edificio de la escuela contrasta con el horizontal de la piscina; y, asimismo, el fuerte movimiento de líneas de los elementos de cerramiento y cubierta de la piscina, con los volúmenes de las edificaciones circundantes.

El nivel de la piscina está aproximadamente $2,50 \mathrm{~m}$ por encima del suelo, con el fin no sólo de mejorar la visión y disfrute del paisaje y el soleamiento de la piscina, sino también de impedir que ésta se vea tanto desde la calle como desde el patio de la escuela. 
En cuanto a la distribución, la planta baja del edificio dedicada a piscina cubierta comprende: el hall de entrada, la caja, control, los vestuarios, duchas, lavabos, diferentes instalaciones - bombas para la circulación del agua, sistemas de filtros, etc.-, gimnasio, local para guardar los aparatos gimnásticos, sala del profesor monitor, etc.

La planta baja del edificio de la Escuela de Comercio alberga: la zona de ingreso, hall, tres clases, cafetería, portero, almacén, vivienda del portero, etc.

La planta superior contiene: las piscinas -una reglamentaria y otra para enseñanza-, bancos calientes, restaurante, cocina, vestuarios y lavabos para ambos sexos, etc.

En la parte correspondiente a la Escuela de Comercio: las aulas, la biblioteca, despacho del director, sala de profesores, administración, etc.

El utilizar grandes superficies acristaladas en las fachadas del edificio de la piscina es consecuencia de la consideración de razones de orden urbanístico y técnicas de ella. La densidad de edificación en este sitio requería ya de por sí una estructuración transparente, y el obtener una muy buena iluminación en la piscina ayuda a aumentar la sensación de seguridad en los usuarios de la misma.

La inclinación de las dobles paredes de cristal reduce el volumen del edificio y hace difícil mirar, desde fuera, el interior del edificio. La luz diurna entra, además, con una inclinación apropiada para que apenas se produzcan sombras violentas en el interior.

Como características constructivas del edificio mencionaremos: que la forma convexa del techo ayuda a la absorción de los sonidos, y está acondicionada, asimismo, para aumentar el aislamiento acústico; la escuela y la piscina tienen común el servicio de calefacción; el depósito elevado de la piscina está situado en la parte alta de la escuela.

Como materiales de construcción se han utilizado: hormigón visto, acero, y fábrica de ladrillo claro visto.

En las fachadas se han empleado aluminio y cristal en los muros de cerramiento exteriores; y en el interior se ha utilizado madera, cuyo tono caliente contrasta con las baldosas de color blanco y gris claro y con los revestimientos de las paredes realizados a base de cerámica esmaltada.

En el edificio de la escuela, la organización escalonada de las clases ayuda a conseguir la ideal descongestión del denso agrupamiento de aquéllas, frecuente en las escuelas clásicas. Las ventanas dan al oeste, contrariamente a las normas usuales; sin embargo, las persianas laminares instaladas al exterior limitan el soleamiento y el molesto caldeamiento consiguiente.

En la planta baja, el edificio de la escuela presenta algunos espacios diáfanos entre pilares; y entre el hall de la escalera, generosamente acristalado, y el hall de recreo, cubierto, ha sido creada una sala de estar para los alumnos.

Adaptado por J. M. Rubio 


\section{Piscine mumicipale et école de commerce ì

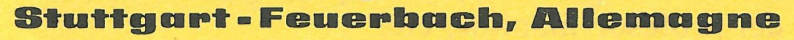

Manfred Lehmbruck, architecte Dr. Ing.

Le rez-de-chaussée de l'édifice de la piscine municipale couverte comprend le hall, la caisse, les vestiaires, les douches, le gymnase, etc., et celui de l'édifice de l'école de commerce, trois classes, la cafeteria, le logement du concierge, etc.

Au niveau supérieur du premier édifice se trouvent les piscines - l'une réglementaire et l'autre destinée à l'enseignement de la natation-, les vestiaires, les lavabos, etc. Le niveau supérieur de l'école de commerce est occupé par les classes, la bibliothèque, la salle des professeurs, le bureau du directeur, l'administration, etc.

Cet ensemble, de grande beauté plastique, a été conçu avec un profond sens de l'urbanisme.

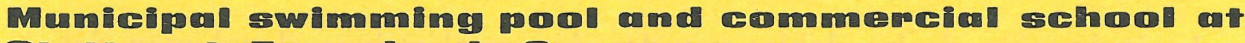

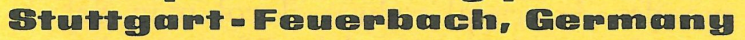

Manfred Lehmbruck, Dr. Eng.

On the ground floor of this project there is a hall, a ticket office, dessing rooms and showers, and a gymnasium; whilst the commercial school building has three classrooms, a cafeteria and the porter's room.

On a higher level there are two swimming pools, a full sized one and one for beginners, dressing and washing rooms. The commercial building has further classrooms, a library, a teachers' room, the director's study and offices, on the second floor.

The whole construction is of great plastic beauty and has been planned with extreme urbanistic purpose.

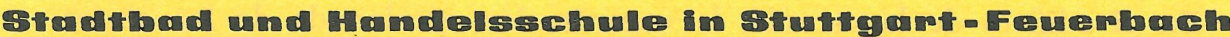 Deutsechland}

Manfred Lehmbruck, Architekt, Dr. Ing.

Im Erdgeschoss des Städtischen Hallenschwimmbades befiinden sich die Halle, die Kasse, die Umkleideräume, Duschen, die Turnhalle, usw. Im Erdgeschoss der Handelsschule sind drei Klassenräume, der Erfrischungsraum, die Hausmeisterwohnung, usw. untergebracht.

Im Obergeschoss des Schwimmbades befinden sich die Schwimmbecken - das Sportbecken und das Lehrschwimmbecken -, Umkleideräume, Waschräume, usw. Im Obergeschoss der Handelsschule sỉnd die Klassenräume, die Bibliothek, das Lehrerzimmer, das Rektorbüro, die Verwaltung, usw. untergebracht.

Der neue Gebäudekomplex weist eine grosse Formschönheit auf und ist vom städtebaulichen Gesichtspunkt sehr gegliickt. 